\title{
Curriculum Leadership: Reforming and Reshaping Successful Practice in Remote and Regional Indigenous Education
}

\author{
Robyn Jorgensen (Zevenbergen) \\ Griffith University \\ $<$ r.jorgensen@griffith.edu.au>
}

\begin{abstract}
The importance of leadership in changing schools and building quality programs is the focus of this paper. While leadership is often seen as a management aspect of school life, the role of leadership in curriculum change may be quite different from that of school leadership visa-vis the principal. In small remote schools where there are many factors impacting on school reform, this paper explores curriculum leadership where the schools successfully performed against numeracy benchmarks. Features of curriculum leadership are drawn from these cases to develop a framework for considering effective leadership in remote Indigenous contexts.
\end{abstract}

Leadership in schools comes in many forms and extends beyond the role of the formal leadership roles, such as Principals and management structures. The principalship is often perceived to be a position synonymous with school leadership. The role is integral in leading and managing schools and may provide vision for the school. Many managerial tasks are part of the principal's brief in terms of overall management and accountability within schools, so some aspects of leadership may be taken by other members of the school community. Leadership comes in many forms and through a range of roles both formal and informal. Curriculum leadership may fall into the ambit of the principal but may also be part of a devolved or distributed model of leadership where a key teacher may assume a role in leading curriculum innovation. As such, curriculum leadership may be an amorphous role within the structure of the school and fall to a person or group of people who assume responsibility for curriculum as a whole or for a particular curriculum area such as mathematics/numeracy. This paper explores the ways in which curriculum leadership was enacted across a number of schools in the Northern Territory. The overall study that is the basis of this paper was to examine the practices at nineteen schools across the Northern Territory that had been successful in literacy and numeracy in the national testing scheme in 2010, and the results published in 2011. This paper draws on the numeracy practices around curriculum leadership in these schools.

\section{Curriculum Leadership}

Within the literature on school leadership, there is some consensus that there are a number of key principles that are core to successful school leadership. Leithwood et al (2006) suggest that these include: "building vision and setting direction; understanding and developing people; redesigning the organisation; and managing the teaching and learning program". The importance of the principal in providing vision and strategic direction for the school is critical to the overall direction of the school. In many small schools, the principal may take on the role of leader and manager as well as curriculum leader. The principal may have particular leadership style within the school and share leadership and roles across the school through to being quite autocratic in decision making. The complexity of schools, systems and personalities shape the possibilities of curriculum leadership.

Principals exert an influence on student outcomes (broadly conceived) through a focus on teaching and learning which is driven by their own values and vision, an agreed school vision, elements of transformational leadership, and increasing school capacity, across four dimensions (personal, 
professional, organisational, and community), taking into account and working within the school context, and using evidence-based monitoring, and critical reflection to lead to change and transformation. (Drysdale, Goode \& Gurr, p.699).

Undeniably, the principal has a key role in the overall school culture and direction. In their study of leadership and principals, Walters et al (2003) reported the strong relationship between the impact of the leadership and student achievement. The principal was key in terms of quality curriculum but inclusive of the overall school environment and support mechanisms within the school. These elements are clearly important in terms of the culture of the school, but for this paper, I would move away from the role of the person to the characteristics of curriculum leadership so that these may apply to the principal or equally to another staff member who is taking on this role.

The notion of distributed leadership closely aligns with the devolution of curriculum leadership to key staff members within the school community. In some cases, the devolution of curriculum leadership within the school may be a strategic decision that aligns with the vision of the school to be inclusive of the strengths of the staff (and possibly students). Alternatively, the move to involve staff in curriculum leadership may be more of an ad hoc or opportunistic decision where a particular staff member may have an interest in the area. As such, Gronn (2002) has argued that the social context of the school must be considered when investigating the impact and roles of leadership within a particular site.

Policies, such as national testing or curriculum, can be contentious and open to interpretation. In the rollout of a curriculum reform in Queensland, it was found that principals and teachers had very different approaches in how they interpreted and enacted the curriculum (Niesche \& Jorgensen, 2010). Hayes et al (2004) have argued that there is a need for productive leadership to be considered in how different interpretations of policy are not only possible, but of considerable value, as the contexts in which policies are implemented can vary considerably. More specifically, in schools where there are challenging circumstances, Harris (2002) reported that it was important to have devolved models of leadership so that staff could build positive relationships across the school and where staff were empowered to lead.

It is in the context of National Testing and the outcomes of these tests, that this paper explores curriculum leadership. There were a number of schools identified in the Northern Territory that were successful when compared with similar schools, on their literacy and/or numeracy test results. Identifying the successful practices at these schools was part of a larger study. One of the elements of success was the leadership around numeracy (and literacy) curriculum. It is within this very broad conceptualisation of leadership, that the enactment of numeracy reforms aimed at improving student performance was studied. The contexts of the schools were remarkably different and hence shaped the possibilities of reform and leadership.

\section{Approach}

The study was part of a research consultancy for the Northern Territory Department of Education and Training (NT DET). NT DET nominated the nineteen schools as having performed well on National Assessment Program for Literacy and Numeracy (NAPLAN), either scoring above similar schools or having improved their scores over time. The schools were in Darwin Region, Alice Springs Region or in remote sites across the Territory. The study was to document the practices at these sites to understand what was happening at these schools in order to build stories of success to share with other teachers in the NT.

Ten sites were visited and for the others, being in very remote (and difficult to access) locations, staff members were interviewed by telephone. In the sites visited, lessons were 
observed and interviews conducted with staff involved with the literacy and numeracy practices at the school. Across all sites, documents and photographs of the key practices contributing to success were collected. The stories were those from the schools. It was not the intent of this study to show if there were a correlation between the practices and the scores as this was not possible within the timeframe and budget. What was sought were vignettes from the schools that documented their practices that could be seen to contribute to success.

All schools were government schools but as the schools varied in size and composition, as well as age cohorts, the number of participants varied for each school. The principles for interviewing were to include the principal to gain a sense of the vision of the school and the overall context; staff involved in the teaching of numeracy and curriculum development; any support staff involved in the reforms at the schools, and any Indigenous education workers associated with the curriculum reforms. Most site visits were for a full day but in some of the larger schools, two days were spent at the school. Two researchers visited each site.

Interviews were shaped to the role of the personnel but were targeted to identify the context of the work; the practices undertaken at the school; the way/s in which reforms had been developed, implemented and evaluated; the roles of people involved in the curriculum innovations; and the perceived benefits of the programs at the school. The telephone interviews were recorded as a record of summary. The data presented in this paper have been drawn from the summary records and then created as a narrative around the discussion points. This paper explores the practices of numeracy leadership in diverse settings. From the cases involved in this study, key principles that were drawn from the study will be highlighted.

\section{Contexts and Curriculum Leadership}

Initially considering the data, the responses will be clustered into two main groups. These groups are based on the size of the schools as the practices in the larger, regional centres were markedly different from the small schools in the more remote contexts. These latter schools were usually two to four teachers with the principal in a teaching/principal role. All schools, except two - one in Darwin and one in a remote setting -- had large numbers of Indigenous students. In the regional settings these may have had between 35\%$50 \%$ Indigenous students whereas the remote, smaller schools (except one) were predominantly all Indigenous students.

\section{Devolved Leadership}

The predominant model for leadership was that of devolved leadership where Principals had involved other staff in key decision-making related to the numeracy programs within the school. In one school, the Deputy led the development of a common approach across the school in terms of both curriculum and assessment. She developed systems that were accessible to all staff so that student achievement was transparent. Also, she ensured that successes by teachers and students were part of the public space within the school. Having transparent processes that all teachers were expected to participate in had become part of the school numeracy program. This process had taken nearly three years to develop, implement and embed across the school.

Deputy: When I commenced at the school there was no numeracy program. Teachers were able to do anything they liked. I came from Victoria where core programs across the school were part of the school culture. So, I looked at the numeracy programs we had, and in consultation with the teachers 
we chose to use one program that we then did professional development around. Also, there was no common testing program for numeracy across the school, so I looked at the available tests and made some decisions about what we needed. All teachers now use these tests and the school results are recorded on a common database. All teachers have access to this so they can see where their students are, and where they were the year before. Growth is important to us as a school. I draw on the expertise of the teachers in terms of the practices we use to support the school program. One teacher in particular is our model teacher and she is used to exemplify good practice to the others.

What was important was that these views were reciprocated in the interviews with the teachers and other staff at the school, indicating that the practices had been embedded within the school and had not remained at the level of rhetoric. This devolution of curriculum leadership was evident in both numeracy and literacy reforms at the schools but it was very much shaped by the context of the school.

\section{Regional Schools}

The larger schools with more than 300 students were based in either the Darwin or Alice Springs regions. These larger schools had a full-time designated principal and at least a deputy principal who may have been full-time or involved in minimal teaching. In these schools, the deputy principal typically led curriculum reform. The models employed at the 4 schools were largely devolved leadership where the Deputy acted in a leader/co-ordinator model and worked with other staff members to support and build the numeracy program. In all schools, there was a key person who used data to inform actions and build appropriate scaffolding programs. This might have been the Deputy but also included a key teacher who had an interest in co-ordinating data. The data included test results from NAPLAN and enabled schools to monitor how they were progressing and areas of weakness in the school numeracy programs. All schools, except one, also used other data to inform their numeracy education practices. The one school that relied heavily on NAPLAN data was a predominantly middle-class school with a very small (almost negligible) Indigenous student cohort.

Principal: At this school, I decided to continue the work of the previous principal as he had worked tirelessly to ensure quality program. As the Deputy had worked closely with him, she has taken over the reins of the numeracy (and literacy) program. She knew what had happened in the past and has been able to build on that. Also, my background is secondary school so she is expert in primary, particularly early years so she knows what has to happen in those formative years. She is much more expert than I am on this so I am happy for her to continue the great work that has been strongly embedded in the school and in the knowledge of the teachers.

\section{Remote Schools}

The situation was quite different in the remote schools where there were frequently only two teachers and the principal had a teaching-principal role. There was little scope for devolution of leadership as there were few people for the sharing of load and ownership. In the cases in this study, the principals had been very successful in working with their teachers to develop numeracy programs of which the staff assumed ownership. In other cases, the lack of expertise/interest in numeracy/mathematics was a challenge in some of the smaller schools, particularly those at the primary level.

Teaching Principal: For me, I am not that good or interested in numeracy so it has been difficult to work out a good program for the school. Professional development is hard to access so I have had to rely on someone [regional curriculum consultant] coming in to help us. I have really found the conversations around numeracy from the consultant to be very valuable in helping to build our numeracy program. 
Teaching/Principal: I have found it difficult to balance the role of principal and all the paperwork we have to do for that, and then to develop a maths program. We have an enthusiastic teacher who has an interest in maths, so she has taken over the coordination of our numeracy program. That will make a difference to have something organized, and a sense of good equipment that can be used properly. I am more than happy for her to take on this role. I am sure she is going to do a great job.

The number of teachers/staff in a school impacts on the possibilities of devolved leadership. This is further exacerbated by the fact that many of the teachers in remote contexts are from interstate and are new to the career of teaching. Building a numeracy curriculum that aligns with the needs of the school, expertise of the staff, and complies with statutory requirements was an important consideration of the work of the schools.

\section{Issues Around Curriculum Leadership}

There were some salient aspects of curriculum leadership that shaped the possibilities for leadership and curriculum reform. These are discussed in this section. A common theme across all schools was the need for consistency in the numeracy programs and transparency so that students and communities were aware of what was constitutive of learning.

Principal: I don't think it really matters what mathematics program we use in the school so long as we are explicit and consistent. What is always a problem is when there is no common or shared program and teachers do whatever they like. It does not work. So if the teachers are all teaching the same way and content is building on each other, then there is scope for learning and growth.

\section{Use of Commercial Programs}

Across most sites, there was a tendency for schools to rely on some sort of commercial program for their numeracy program. As noted in earlier comments, there was a common experience across many of the sites where they sought to find commercially available resources - teaching programs, resources and/or assessment tools - that could be used as the numeracy program. The role of the curriculum leaders involved the selection of resources and their implementation at the school level.

\section{Sustainability}

Perhaps one of the biggest challenges in schools, and particularly remote schools where there is a high turnover of teachers/staff, is sustainability. Often remote principals are on an upward career path and feel they have to make their mark at a school. Many of the comments raised by participants in this study highlighted this issue and is captured in the following comment:

Teacher: New principals come into these schools and need to make their mark so that they can be moved to a new location probably in Alice or Darwin and get a promotion. They have to change what was here even if it was working. Perhaps it would be productive for the system to recognize that it could be a good thing for a new principal to recognize the good work of the predecessor and continue to work with and refine the earlier work.

This results in a constant change in curriculum as new principals come to the school with their ideas. Having consistency in programs was identified by most of the participants in the study yet, most of them also commented on the constant change in provision of numeracy programs within schools. This made it challenging, particularly in remote settings, where the community had a constant change of staff and, with that, a constant change in programs. However, in the regional settings, it was more likely that the staff were staying in the region for extended periods, thus making for longer stays for the teachers and staff, and less impact on change. 
Teacher: It was good when the new principal came in and said we were staying with the program. We had spent a lot of time building resources and on professional development so it was good to continue with it. The whole school is on board so to build it and make it even better was very good.

The situation in the remote schools was slightly different from the above comment. In the remote settings, many factors impact on sustainability and curriculum leadership. In particular, the upward mobility of potential leaders means that they often want/need to be able to demonstrate leadership and hence change programs when they arrive at a remote school. This was particularly noted by principals who had remained in communities for extended periods of time.

Principal: Each time a new principal comes to the school they want to make the school look like what they think is best. The community is sick of changing and they don't know what is going on.

Principal: I have worked in remote areas for a long time and I know the communities are tired of change - every time a new principal comes in. I decided I would keep the numeracy program we had here before and refine it. It was pretty standard stuff so it was not a real issue.

Despite best efforts to build sustainability into numeracy programs, there is the potential for change with the changeover of new staff. In one site, the principal had worked hard with the staff to build a shared curriculum for numeracy (and literacy) in which all teachers had an interest and commitment. She had also worked extensively with the community so that they were aware of the numeracy program. This had included open nights at the school, sending information home to the families, meeting with people from the community and developing an after school homework facility. Indigenous education workers had been employed and trained in the numeracy program and were able to act as conduits between the school and community. However, during a term's leave, a relieving principal was placed in the school and had revised all the programs so that when the substantive principal returned to the school, many of the programs had been changed. She felt demoralized that a temporary person would have created such changes, and as a consequence, did not feel energized to revisit and return to the programs that had been developed earlier. In her interview she expressed disappointment to have thought she had built in many strategies for sustainability only to find that the programs were changed so much in a 10-week term by a temporary principal.

In considering sustainability and curriculum leadership in this context, it would appear that there is some tension between sustainability and the accreditation process where upwardly mobile leaders are implicitly encouraged to create new learning environments that demonstrate their leadership capacity. This engenders a climate of change and hence risks the stability in programs that may offer greater potential for learning among remote communities. Curriculum leadership may be considered around notions of change, but it may also need to be considered as a skill to recognize quality practice and build on existing practices.

\section{High Expectations}

Teachers, staff and community need to have high expectations of the students as well as themselves. This was evident in all schools in this study, and the numeracy curriculum was expected to have high expectations of learning - of staff and students.

Principal: I have encouraged teachers to model what they expect of the students. They have to be back in their classrooms before the bell rings so that they are ready to take the students inside. This helps the students know the hidden curriculum of school.

There needed to be high expectations of the students in terms of what they could learn mathematically. This was reflected in the reforms. 
Principal: We needed to ensure that the teachers had high expectations of the students. They needed to make sure that the [numeracy] program reflected high levels of learning rather than low standards and basic skills that they had been doing for years.

Teacher: We have built the numeracy curriculum around expected levels of numeracy. The children do the same content that you would see in a school in Alice or Darwin.

While these comments indicate the staff at the schools saw the importance of high expectations, there was a lot of commentary about the challenges of moving staff away from deficit models of learning to models that reflected high expectations. This was an important component of curriculum leadership.

\section{Curriculum Leadership and Community}

In many remote locations, the school is part of a community. Relationships between staff, curriculum and community are critical to success. For communities to feel that they know what is happening at the school and feel some sense of connection with the programs, curriculum leaders worked with community to develop the programs and to keep community members informed on the on-going implementation of the programs. Some schools had worked very closely with their communities to develop numeracy programs that built the necessary knowledge and skills inherent in school curriculum policy documents as well as working with the needs and interests of the community.

Principal/Teacher: When I started here, I spent a lot of time talking to the community about what they wanted and what I would like to do. This helped me know where we needed to go with our programs. We have times where we show the families to help their children with some of the maths work we are doing. They commented on how much they appreciated not only knowing what the kids did, but also how they were doing their maths.

VET Teacher: We talked with the people in community and they wanted their kids to be able to get jobs and do things. We started "The Shed" with all the tools they would need to build things. They have had to do a lot of maths just to design The Shed, but also now when they build things, there is a lot of maths they need - in the design and budget for example. The students (secondary) love it and the younger ones can't wait to get to do things in the shed. It is very practical and the community can see the value in the students learning how to use tools. So they are getting the practical knowledge they need but also it is strongly linked to many mathematical ideas. It works brilliantly for these kids who are very practical in their thinking.

Some schools had created social functions to attract families to the school. This is a critical role in many communities where there are few opportunities for social gatherings as there are no venues for the events found in regional and urban settings. As such, the school can become the hub of the social life of a community.

Being able to operate a school flexibly as the principal immediately above outlined meant that he had scope to shape the timetable. In this case the school operated on longer days from Monday through to Thursday and then only in the morning of Friday. The students could go home and rest, and the school could be prepared for the evening event.

\section{Conclusion}

Curriculum leadership is critical to the development of quality and appropriate numeracy programs. The context of the school will have influence on the practices of leaders and their success in curriculum reform, implementation and evaluation. In this study, larger schools were able to adopt a devolved leadership model for curriculum but this was restricted in smaller schools due to the number of staff in those schools. Smaller schools were based predominantly in communities and curriculum leadership in these sites included leadership within the community so that Indigenous families were informed and shared the 
vision of the numeracy curriculum. Numeracy curriculum leadership in all schools focused on developing coherent and shared curriculum and assessment practices across the school.

Curriculum leaders had a number of challenges in their capacity of leaders as they built quality programs. Sustainability of numeracy programs within schools was under threat for a range of reasons. Perhaps most significantly was that new leaders come into schools wanting to shape programs in order to demonstrate leadership. In terms of sustainability, and in the community interests, it may be more prudent for curriculum leaders to recognize the strengths of existing programs and maintain and build on existing programs. This model of curriculum leadership is somewhat incongruent with perceptions of leadership and the need to change as demonstration of leadership.

\section{References}

Bezzina, C. (2012) “The road less travelled”: Professional communities in secondary schools. Theory into Practice, 45(2), 159-167

Drysdale, Goode, \& Gurr, (2009) An Australian model of successful school leadership: Moving from success to sustainability. Journal of Educational Administration, 47 (6), 697-708

Gronn, P. (2002) Distributed Leadership. In K. Leithwood, P. Hallinger, K. Seashore-Louis, G. FurmanBrown, P. Gronn, W. Mulford, \& K. Riley (Eds.) Second International Handbook of Educational Leadership and Administration, Dordrecht: Kluwer

Leithwood, K., Day, C., Sammons, P., Harris, A. \& Hopkins, D. (2006), Seven Strong Claims about Successful School Leadership, National College of School Leadership, Nottingham.

Niesche, R. \& Jorgensen, R. (2010). Curriculum reform in remote areas: The need for productive leadership. Journal of Education Administration. 48 (1),.

Walters, T. W., Marzano, R. J. \& McNulty, B. (2003) Balanced leadership: What 30 years of research tell about the effect of leadership on student achievement: A Working paper. McRel. 